\title{
Design Optimization of a Hybrid-Excited Flux-Switching Machine for Aircraft safe DC Power Generation using a Diode Bridge Rectifier
}

\author{
Andre Nasr, Sami Hlioui, Mohamed Gabsi, Mathieu Mairie and Didier Lalevee
}

\begin{abstract}
This paper presents a design optimization methodology of a Hybrid-Excited Flux-Switching Machine (HEFSM) for aircraft DC power generation. Hybrid machines are favored in new aircraft embedded generation systems because of their high power density. Their flux control capability allows the use of the more reliable diode bridge rectifier and makes them suitable for wide-speed-range DC power generation. However, in order to respect aviation safety requirements, these machines must have a limited remanent voltage and therefore an optimal design is needed. At first, the electromagnetic performances of the HEFSM are studied using a transient FE model. In order to perform design optimization, a static method is used instead. This method is shown to be much less time consuming and more suitable for optimization routines. The results have shown very promising performances of the new design. Despite having a very small remanent voltage, high power density has been still achieved.
\end{abstract}

Index Terms-DC power generation, flux-switching machine, finite element modeling, hybrid excitation, multiobjective optimization.

\section{INTRODUCTION}

$\mathbf{O}$ PTIMIZATION has become nowadays a very important procedure in electrical machines design. The need to increase power density in embedded power systems has pushed designers to use optimization techniques in order to increase the overall performances of their machines using available materials and technologies [1]. Permanent Magnet (PM) machines used in electric vehicles have been largely developed in the last decade using such techniques providing compact and very efficient systems at rated speed. However, their high remanent air-gap flux causes safety concerns in aircraft power generation. In case of sudden loss of power electronics and in the event of a fault, these machines may generate an uncontrolled high short-circuit current which can severely damage the windings and cause fire. Moreover, in

Manuscript received March 02, 2017; revised May 18, 2017; accepted June 18, 2017.

A. Nasr and M. Gabsi are with the SATIE Laboratory of ENS Cachan, France (e-mail: anasr@satie.ens-cachan.fr; mohamed.gabsi@enscachan.fr).

S. Hlioui is with the SATIE Laboratory and the CNAM Paris, France (e-mail: sami.hlioui@satie.ens-cachan.fr).

M. Mairie and D. Lalevee are with the TAES group of THALES avionics, France (e-mail: mathieu.mairie@fr.thalesgroup.com; didier.lalevee@fr.thalesgroup.com). case of DC generation, PM machines must be associated with active rectifiers in order to allow power control, reducing in the process the reliability of the overall system. For these reasons, nearly all aircraft use the three-stage wound-field brushless synchronous generator. The main advantage of this machine is safety since it can be easily de-energized by simply cutting the excitation current. Its three-stage structure avoids the use of undesired slip rings and brushes while its field winding offers an efficient control of the excitation flux. This allows DC power generation using the more reliable Diode Bridge Rectifier (DBR).

Design optimization of electrical machines is a multiobjective problem in which the objectives must be carefully chosen depending on the application. In electric vehicles, reducing size and cost is of major interest while on aircraft, weight comes out on top of the list. In order to perform a reliable optimization, high-fidelity models and appropriate optimization algorithms are required. The latter can be classified into two categories : Deterministic and Stochastic. Deterministic algorithms don't always guarantee a global minimum. Convergence in such algorithms depends on a lot of factors like the starting point and often a local minimum is found instead [2]. For this reason, designers usually prefer stochastic algorithms such as the Genetic Algorithm (GA) or the Particle Swarm Optimization (PSO) [3]. Such methods can search a high dimension design space in a computationally efficient manner [4]. Moreover, they all fall into the class of populationbased algorithms and parallel processing techniques can therefore be used [5]. In order to evaluate objective functions, high-accuracy models with fast computational speed would be the perfect choice. However, such models don't really exist and a compromise is usually required between finite element and analytical methods. Semi-analytical models like magnetic equivalent circuit are often used in optimizations, however, their fidelity is not always guaranteed through the whole solution space and their establishment may require a lot of time.

This paper presents a design optimization methodology of a Hybrid-Excited Flux-Switching Machine (HEFSM) for aircraft DC power generation using a finite element model. The use of hybrid-excited machines is favored in new aircraft power systems in an attempt to increase the power density. However, in order to respect aviation safety regulations, these machines must have a limited remanent voltage, and therefore a compromise is needed between high performance and safety. 


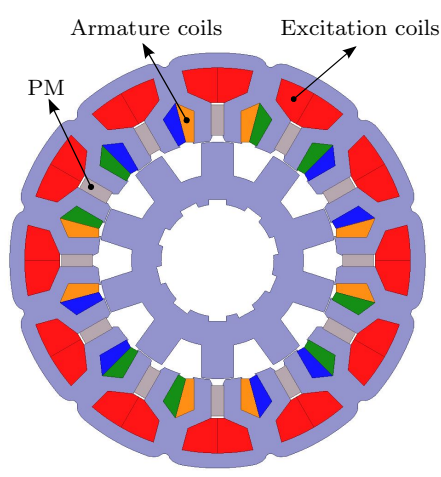

Fig. 1. HEFSM cross section showing the active parts in the stator

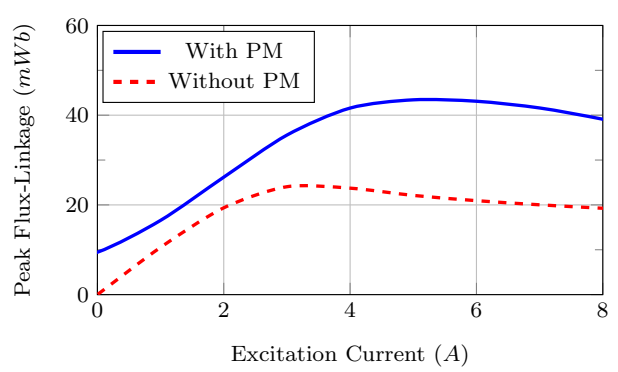

Fig. 2. No-load peak flux-linkage with and without PM

After presenting its design and operating principles, the electromagnetic performances of the HEFSM are simulated using a transient finite element model. Experimental measurements have been also performed on a $3 \mathrm{~kW}$ prototype in order to validate the simulation results. Later on, a design optimization methodology using a static finite element model is presented in order to maximize the generated power while limiting the remanent voltage to very low levels. Some techniques to reduce computation time are presented as well. The optimal design of the HEFSM has shown very promising performances. Despite having a very small remanent flux-linkage, high power density has been still achieved. This result is very interesting as it makes the HEFSM a good candidate for future aircraft DC power generation.

\section{HEFSM DESIGN AND OPERATING PRINCIPLES}

The HEFSM has lately been the subject of many studies [6]-[8]. Its passive rotor makes it very interesting for high speed operations while the positioning of all active parts in the stator avoids the use of sliding contacts and makes thermal evacuation an easier task [9], [10]. The structure studied in this paper has a 10 poles salient rotor [11]-[13]. The cross section of the HEFSM in Fig. 1 shows that the stator is composed of 12 elementary cells each containing an armature coil, a permanent magnet and a slot for the excitation winding. Each of the 3 phases of this machine is made of 4 coils connected in series and shifted by 90 mechanical degrees. Fig. 2 shows the no-load peak flux-linkage versus the excitation current $\left(I_{e x c}\right)$ with and without permanent magnets. The excitation coils give this machine a high capability of flux-regulation which is a very important characteristic for wide-speed-range DC power

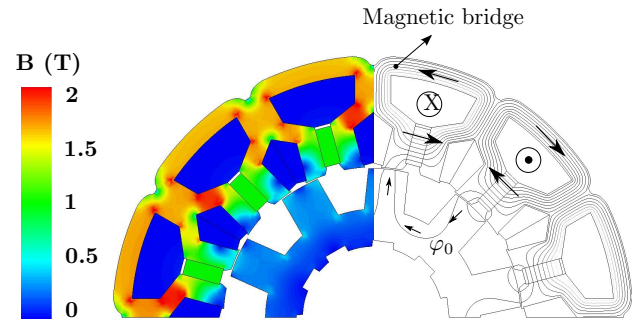

(a) $\mathrm{I}_{\mathrm{exc}}=0 \mathrm{~A}$

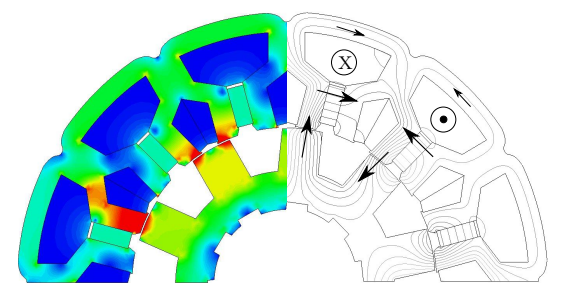

(b) $\mathrm{I}_{\mathrm{exc}}=5 \mathrm{~A}$

Fig. 3. No-load flux lines and flux density patterns in the HEFSM

generation because it allows the use of diode bridge rectifiers [14]. The use of PMs in this machine increases the maximum flux value reached by a factor of 2 . This is of course the aim of using hybrid machines : Permanent magnets create a constant flux-linkage which is added to a variable flux created by the excitation coils. This leads to a controllable total flux-linkage $\phi_{\text {tot }}$ as shown in (1) :

$$
\phi_{t o t}=\phi_{P M}+K I_{e x c}
$$

with $\phi_{P M}$ the flux created by the permanent magnets and $K$ the mutual inductance between armature and field windings. This relation can be applied on all classic hybrid machines but in our case, it doesn't fit with the flux-linkage profile given in Fig. 2. We can notice that the maximum flux for the two cases (with and without PM) is not reached for the same excitation current. Using PM, the maximum is reached for $\mathrm{I}_{\mathrm{exc}}=5 \mathrm{~A}$ while in the other case it is reached for $\mathrm{I}_{\text {exc }}=3 \mathrm{~A}$. This fact conflicts with the relation given in (1) ( $K$ is considered as constant). In order to understand how the flux sources combine in the HEFSM, we give in Fig. 3 the no-load flux lines and flux density patterns for $\mathrm{I}_{\mathrm{exc}}=0$ and $5 \mathrm{~A}$. At $\mathrm{I}_{\mathrm{exc}}=0 \mathrm{~A}$, the majority of the flux created by the permanent magnets completes its loop in the magnetic bridge in the stator yoke and only a small part $\left(\varphi_{0}\right)$ passes through the air-gap forming the remanent flux (Fig. 3(a)). Surprisingly, this is not what we usually expect from a hybrid machine because the potential of the permanent magnets to reinforce the flux-linkage is somehow ignored by the magnetic bridge. On the other hand, we can notice that once applied, the current in the excitation coils will lead to an opposing Magneto-Motive Force (MMF) to the one created by the permanent magnets in the yoke. This takes us to Fig. 3(b) where the resulting MMF shifts direction and the flux is circulating in the opposite way. At this point, the yoke is less saturated but the air-gap flux-linkage increases significantly. These two operation points $\left(\mathrm{I}_{\mathrm{exc}}=0 \mathrm{~A}\right.$ and $\mathrm{I}_{\mathrm{exc}}=5 \mathrm{~A}$ ) show that despite having a low remanent voltage, the HEFSM can still reach high flux-linkages (Fig. 


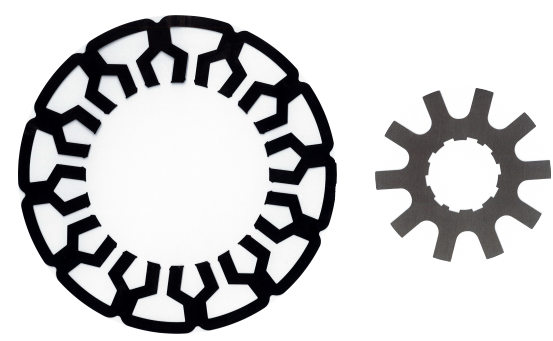

Fig. 4. Stator and rotor prototype sheets

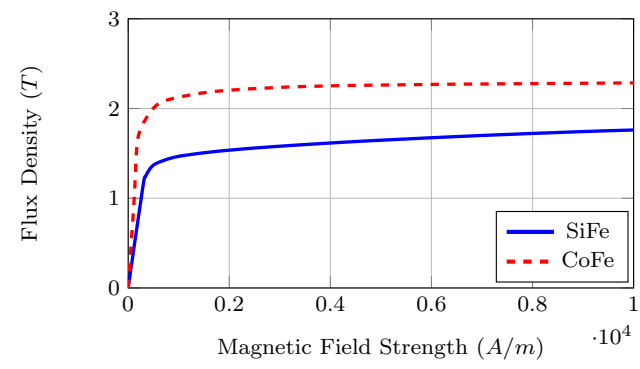

Fig. 5. B-H magnetization curves for $\mathrm{CoFe}$ and $\mathrm{SiFe}$

2). This is due to the special stator structure with the magnetic bridge that offers a high flux control capability [15]. The use of permanent magnets in the HEFSM delays the magnetic saturation of the yoke which makes the excitation winding much more efficient and allows higher flux-linkages, while on the other hand, with no permanent magnets used, the yoke would have saturated at $\mathrm{I}_{\mathrm{exc}}=3 \mathrm{~A}$ as shown in Fig. 2. We can also notice in this figure that for high excitation currents, the flux-linkage decreases for both cases. This is because of the saturation in the stator teeth that favors flux leakage in the air-gap. Even at $\mathrm{I}_{\mathrm{exc}}=0 \mathrm{~A}$, we can notice some highly saturated regions due to the PM flux. This saturated nature of the HEFSM makes analytical modeling totally unreliable and favors FE methods.

\section{HEFSM MODELING AND EXPERIMENTAL VALIDATION}

In order to simulate the electromagnetic performances of the HEFSM associated to a DBR, a 2D Transient Finite Element (TFE) model has been used ${ }^{1}$. This model allows to simulate transient and steady-state behavior of the machine, however in our case, the eddy currents and their effects were not taken into account. Experimental measurements have also been performed on a $3 \mathrm{~kW}$ prototype and will allow us to approve the model's validity in determining the no-load flux-linkage, the short-circuit current and the DC generated power over a large range of excitation currents. Fig. 4 shows the stator and rotor sheets of the $3 \mathrm{~kW}$ prototype. They are respectively made of cobalt-iron $(\mathrm{CoFe})$ and silicon-iron $(\mathrm{SiFe})$. The use of $\mathrm{CoFe}$ is very common in aviation and space applications [16]. It can reach a very high saturation flux density (Fig. 5) and has specific losses comparable with those of the best silicon-iron alloys. $\mathrm{SiFe}$ has been used in the rotor in order to reduce costs. This prototype was designed to deliver its

${ }^{1}$ Ansys Maxwell 16.2.0
TABLE I

PROTOTYPE SPECIFICATIONS

$\begin{array}{ll}\text { Number of stator elementary cells } & 12 \\ \text { Number of rotor teeth } & 10 \\ \text { Number of phases } & 3 \\ \text { Number of turns per armature coil } & 28 \\ \text { SmCo PM residual induction } & 1.1 \mathrm{~T}\left(20{ }^{\circ} \mathrm{C}\right) \\ \text { External stator diameter } & 140 \mathrm{~mm} \\ \text { Stack length } & 35 \mathrm{~mm} \\ \text { Air-gap } & 0.35 \mathrm{~mm} \\ \text { Nominal power } & 3 \mathrm{~kW}\end{array}$

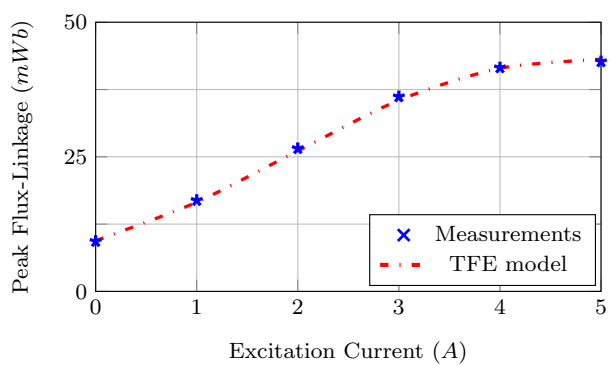

Fig. 6. No-load flux-linkage comparison

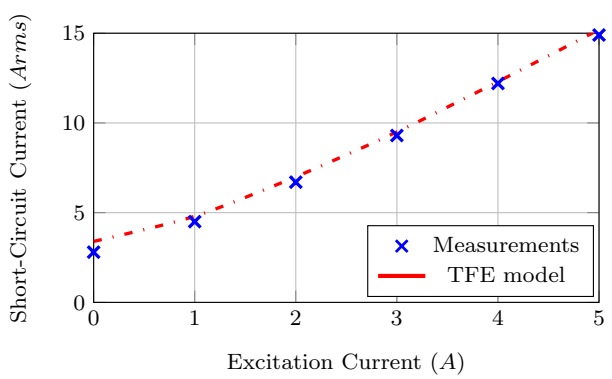

Fig. 7. Short-circuit current comparison

nominal power between 6000 and $13000 \mathrm{rpm}$. It has 28 turns per armature coil and 12 Samarium-Cobalt ( $\mathrm{SmCo}$ ) permanent magnets as shown in table I. Its external stator diameter is equal to $140 \mathrm{~mm}$ with a stack length of $35 \mathrm{~mm}$ and an airgap of $0.35 \mathrm{~mm}$. Figure 6 and 7 show respectively no-load flux-linkage and short-circuit current comparisons between the TFE model and measurements. The model shows very good accuracy in determining both characteristics especially in the saturation region for the flux-linkage. We can notice that at $\mathrm{I}_{\mathrm{exc}}=0 \mathrm{~A}$, the remanent flux $\left(\varphi_{0}\right)$ is minimum. This characteristic is very important as the back EMF and the shortcircuit current can be kept at very low levels in case of fault.

The DC output power is determined by coupling the magnetic model to an external electric circuit containing a DBR feeding a $270 \mathrm{~V}$ DC bus as shown in Fig. 8. With such configuration, the fundamentals of both phase voltage $v$ and phase current $i$ are in phase as shown in the first harmonic phase diagram. When power transfer occurs between the generator and the DC bus, the phase voltage RMS value $V$ is constant and is imposed by the DC bus voltage : 


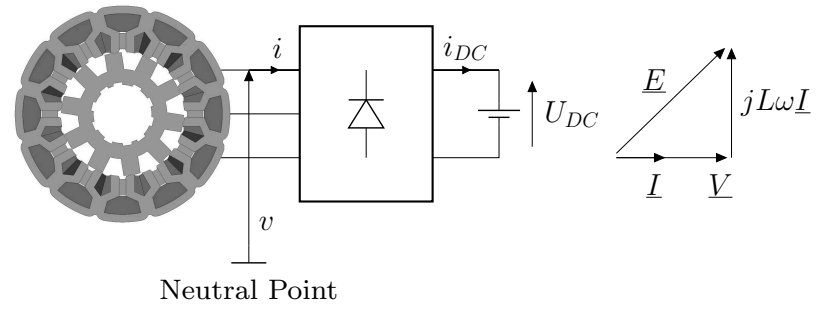

Fig. 8. HEFSM associated with DBR and its phase diagram

$$
V=\frac{\sqrt{2}}{\pi} U_{D C}
$$

Fig. 9 shows the phase voltage and the phase current waveforms for $\mathrm{I}_{\mathrm{exc}}=5 \mathrm{~A}$ at $6000 \mathrm{rpm}$. The shape of $v$ can be explained by the fact that the DBR is characterized by $60 \mathrm{de}$ grees commutation angle due to the large generator inductance [17]. Considering the conversion efficiency of the DBR equal to 1 , the DC electromagnetic power can be determined using (3) :

$$
P_{D C}=U_{D C} i_{D C}
$$

with $U_{D C}$ the DC bus voltage and $i_{D C}$ the rectified current. However, in order to compare the TFE model's electromagnetic power to measurements, "real" electric power $P_{\text {elect }}$ must be determined first by subtracting the core losses of the machine. These latter are determined from measurements (marked with an asterisk *) using the experimental setup shown in Fig. 10 :

$$
P_{\text {coreloss }}^{*}=P_{\text {abs }}^{*}-P_{\text {elect }}^{*}-P_{\text {arm }}^{*}-P_{\text {mech }}^{*}
$$

with $P_{a b s}^{*}$ the absorbed power measured on the drive shaft, $P_{\text {elect }}^{*}$ the measured electric power at the DBR output and $P_{\text {arm }}^{*}$ the copper losses in armature windings. Mechanical losses $P_{\text {mech }}^{*}$ have been measured during a no-load test. Finally, the simulated electric power $P_{\text {elect }}$ can be determined using (5):

$$
P_{\text {elect }}=P_{D C}-P_{\text {coreloss }}^{*}
$$

Fig. 11 shows the measured and simulated DC electric power at 6000 and $12500 \mathrm{rpm}$. The TFE model shows good accuracy and proves its reliability even with the use of the DBR. The maximum power reached at $6000 \mathrm{rpm}$ is around $3800 \mathrm{~W}$ for $I_{e x c}=6 \mathrm{~A}$. We can notice that between $I_{e x c}=0$ and $2.1 \mathrm{~A}$, the power is zero. In fact, in order to have power transfer through the DBR, the back EMF $E$ must reach a minimum voltage $E_{\min }$ :

- $E_{\text {min }}=\frac{\sqrt{2}}{\pi} U_{D C}$

- if $E \leqslant E_{\text {min }}^{\pi}: V=E$ (No power transfer)

- if $E>E_{\text {min }}: V=E_{\text {min }}$ (Power transfer is occurring)

At $6000 \mathrm{rpm}, E_{\min }$ is reached for $I_{\text {exc }}=2.1 \mathrm{~A}$. At higher rotational speeds, power transfer starts at a smaller excitation current (Fig. 11).

Despite its good accuracy, this transient model cannot be used in an optimization routine because it is very time consuming. In fact, in order to determine the output power,

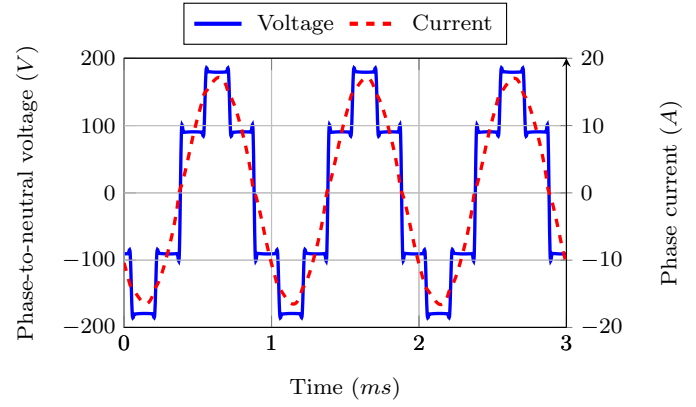

Fig. 9. Phase voltage and phase current for $\mathrm{I}_{\mathrm{exc}}=5 \mathrm{~A}$ at $6000 \mathrm{rpm}$

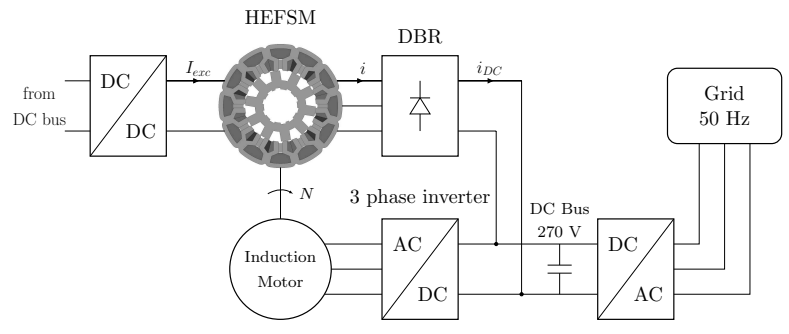

Fig. 10. Scheme of the experimental setup

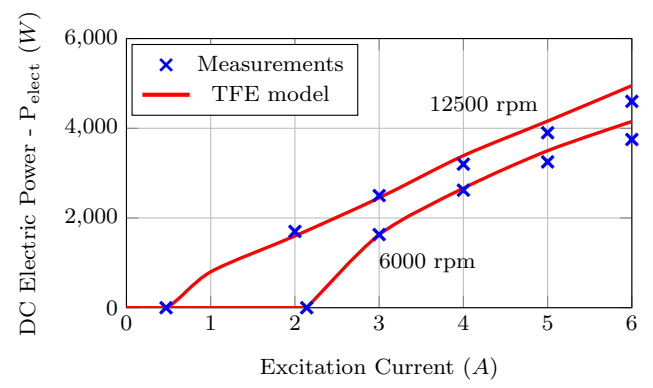

Fig. 11. DC electric power comparison using the transient model

steady state should be reached and at least 3 electrical periods should be considered. This leads to an average simulation time of $15 \mathrm{~min}$ for only one operation point (one excitation current at one rotational speed). A big part of this time is also due to the communication needed between the electromagnetic and the electric model. In order to reduce computation time, we will present in the next section another method to determine the DC power using a Static Finite Element (SFE) model.

\section{DESIGN OPTIMIZATION OF A HEFSM FOR AIRCRAFT DC GENERATION}

The main concern of the prototype presented in the previous section is its high remanent air-gap flux $\varphi_{0}$. In fact, aviation regulations require a very small remanent voltage at maximum operation speed for safety concerns. For $\varphi_{0}=9.3 \mathrm{mwb}$, the remanent DC voltage of the prototype at the DBR output is equal to $210 \mathrm{~V}$. It can be determined using (6) :

$$
U_{D C 0-13000}=\frac{3 \sqrt{3}}{\pi} \omega \varphi_{0}
$$

with $\omega$ the angular frequency equal to $13613 \mathrm{rad} / \mathrm{s}$ at 13000 rpm. Such high remanent voltage is unacceptable on an 
aircraft, therefore, we will present in this section a design optimization methodology in order to limit $U_{D C 0-13000}$ to only $16 \mathrm{~V}$ while maintaining good performances in terms of maximum power reached and efficiency.

\section{A. DC Power calculation using a FE static model}

In order to reduce computation time, a static finite element model will be used instead of the TFE model. A static model means that the rotor is fixed at a certain position so there is no longer a coupling to an external electric circuit. In all the upcoming equations, zero phase resistance has been considered in order to simplify the expressions, however, the phase resistance has been taken into account in the implemented model. Standing on the phase diagram of the machine associated with the DBR given in Fig. 8, the DC electromagnetic power can be determined by :

$$
P_{D C}\left(I_{e x c}\right)=3 V I=3 V \frac{E\left(I_{e x c}\right)}{L\left(I_{e x c}\right) \omega} \sqrt{1-\left(\frac{V}{E\left(I_{e x c}\right)}\right)^{2}}
$$

with $V$ the phase-to-neutral voltage, $I$ the phase current, $E$ the no-load back-EMF and $L$ the phase cyclic inductance. Shortcircuit current $I_{c c}$, peak no-load flux-linkage $\varphi_{M}$ and DC bus voltage $U_{D C}$ can be introduced :

$$
P_{D C}\left(I_{e x c}\right)=3 V I_{c c}\left(I_{e x c}\right) \sqrt{1-\left(\frac{2 U_{D C}}{\pi \varphi_{M}\left(I_{e x c}\right) \omega}\right)^{2}}
$$

We can notice from (8) that the excitation current $I_{e x c}$ is the only parameter that can be used to control the power for a constant speed. A simpler and final version of the power formula can be written :

$$
P_{D C}\left(I_{e x c}\right)=3 V I_{c c}\left(I_{e x c}\right) \sqrt{1-\left(\frac{N_{b}\left(I_{e x c}\right)}{N}\right)^{2}}
$$

$N$ is the rotational speed and $N_{b}$ is a base speed for which $E=E_{\text {min }}$. It can be deduced from (10) :

$$
N_{b}=E_{\min } \frac{30 \sqrt{2}}{\pi} \frac{1}{N_{d r}} \frac{1}{n_{c p} n_{t c} \phi_{M}}
$$

$n_{c p}:$ Number of elementary coils per phase

$n_{t c}:$ Number of turns per elementary coil

$\phi_{M}$ : Peak no-load flux-linkage per turn

$N_{d r}$ : Number of rotor poles

So, in order to determine $P_{D C}$, the no-load flux-linkage $\phi_{M}\left(I_{e x c}\right)$ and the short-circuit current $I_{c c}\left(I_{e x c}\right)$, both dependent on the excitation current $I_{e x c}$, must be determined using the static FE model in d-axis position. $I_{c c}$ cannot be directly calculated using such a model since it only provides flux-linkage as an output. Therefore, the method presented in Fig. 12 was used. By definition $I_{c c}$ is the armature current that cancels the total flux in the three phases for a fixed value of $I_{e x c}$. In d-axis position for phase A, $I_{c c}$ is at its maximum $I_{\text {arm }}$ and is equal to $-I_{\text {arm }} / 2$ in both phases B and C. The goal behind this method is to find the armature current amplitude $I_{c c}$ that cancels total flux with a minimum number of simulations $\phi(I)$. At first we search for two values $\mathrm{I}^{+}$and

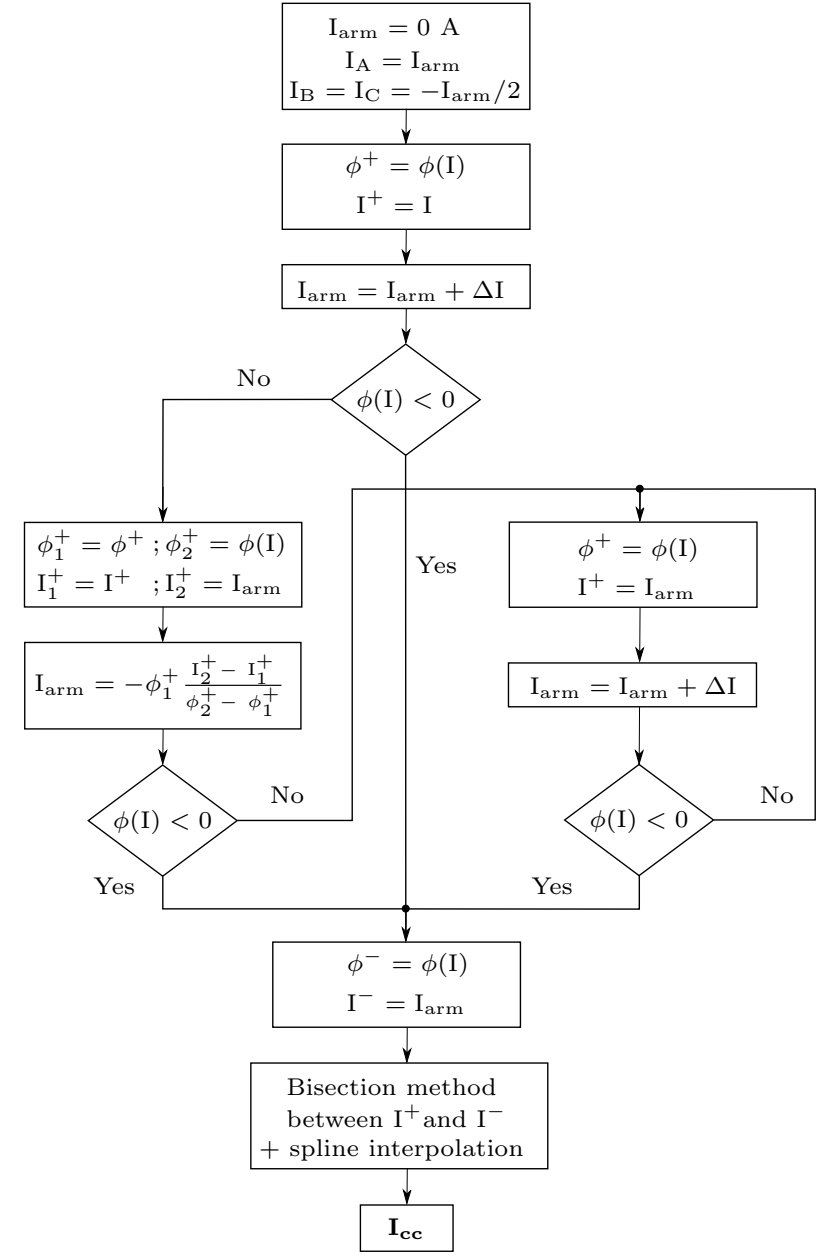

Fig. 12. Flowchart of short-circuit current calculation with static model

$\mathrm{I}^{-}$of the armature current that give respectively a positive and negative total flux $\phi^{+}$and $\phi^{-}$that are the nearest possible to zero. In order to find $\mathrm{I}^{-}$quickly, a linear interpolation is performed in a attempt to get very close to the solution (Fig. 13). Once $\mathrm{I}^{+}$and $\mathrm{I}^{-}$are found, a bisection method is used to determine a prefixed number of points between $\phi^{+}$and $\phi^{-}$ that will be used to perform a cubic interpolation in order to find $I_{c c}$ with a good accuracy. The advantage of this method is that the number of simulations needed to find $I_{c c}$ doesn't depend on the current step used $\Delta I$ neither on $I_{\text {exc }}$. In order to further reduce computation time, we have chosen to save the model's mesh created in the first simulation and to import it into all the other simulations. This is possible because of the fixed geometry of the design in a static model. Once the no-load flux-linkage and the short-circuit current obtained, $P_{D C}$ can now be determined using (9) and (10). Figure 14 shows a comparison between the measured and the simulated DC output power using the SFE model. This model shows very good behavior in determining the output power at 6000 and $12500 \mathrm{rpm}$. The time needed for every operation point is around 2 minutes which is 8 times faster that the TFE model (15 minutes). Moreover, once the no-load flux-linkage and the short-circuit current determined, $P_{D C}$ can be obtained for any rotational speed with no further simulations needed. 


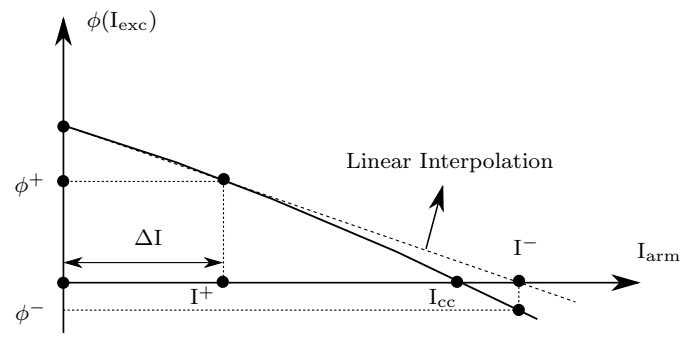

Fig. 13. Short-circuit current calculation using the SFE model

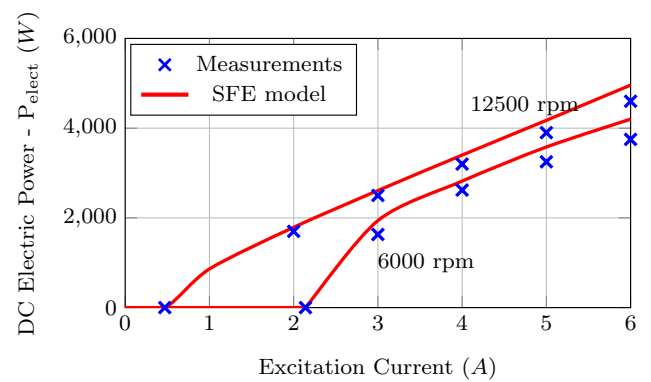

Fig. 14. DC electric power comparison using the static model

\section{B. Design optimization methodology}

After validating the SFE model in the previous section, we will use it in an optimization routine in order to find an optimal design of the HEFSM in which $U_{D C 0-13000}$ is limited to 16 $\mathrm{V}(\mathrm{C} 1)$ as shown in table II. As a second constraint, we will limit the weight of active parts (ferromagnetic sheets, copper and permanent magnets) to $3.5 \mathrm{~kg}$ which is the corresponding weight of the prototype. The first objective of the optimization will be to increase the maximum power reached at $6000 \mathrm{rpm}$ in an attempt to have the best possible power density, an important criteria in aircraft power generation. Finally, we will look to maximize the efficiency at $12500 \mathrm{rpm}$ for the nominal power of $3 \mathrm{~kW}$. It is considered that the generator will run at this speed for most of the flight time. As core losses are not taken into account, efficiency is determined by :

$$
\eta=\frac{P_{D C}}{P_{D C}+P_{e x c}+P_{\text {arm }}}
$$

with $\eta$ the efficiency, $P_{e x c}$ and $P_{a r m}$ the copper losses in the excitation and armature windings considered at $150{ }^{\circ} \mathrm{C}$ with a slot fill factor of $40 \%$. Fig. 15 shows the design parameters of the stator and the rotor. In total we have 14 parameters all listed in table III. 11 of these parameters are optimization variables while the remaining three are either fixed or deduced :

$$
R s e_{0}=70 \mathrm{~mm} ; R r e_{0}=R s i-g ; R i_{0}=R r i-l d r
$$

with $g$ the air-gap. A Multi-Objective Particle Swarm Optimization (MOPSO) algorithm implemented in matlab has been chosen to perform this optimization [18]. Figure 16 shows a flowchart of the overall optimization process. At first, optimization parameters like the desired number of particles Prt and the number of iterations Ite are defined before
TABLE II

\begin{tabular}{|c|c|}
\hline $\begin{array}{l}\text { C1 : } \\
\text { C2 : }\end{array}$ & $\begin{array}{l}\mathrm{U}_{\mathrm{DC} 0-13000}<16 \mathrm{~V} \\
\text { Weight }<3.5 \mathrm{~kg}\end{array}$ \\
\hline Obj1 : & Maximize $\mathrm{P}_{\mathrm{DC}}$ at $6000 \mathrm{rpm}$ \\
\hline Obj2 : & Maximize efficiency at $3 \mathrm{~kW}-12500 \mathrm{rpm}$ \\
\hline $\mathrm{Nb}$ of iterations : & 50 \\
\hline Nb of particles : & 100 \\
\hline Nb of optimization variables : & 11 \\
\hline
\end{tabular}

OPTIMIZATION PARAMETERS
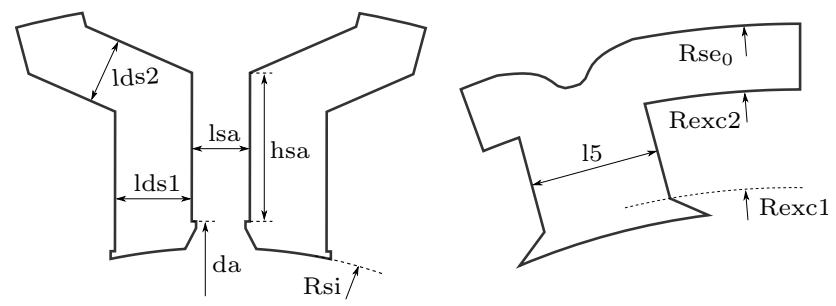

(a) Stator

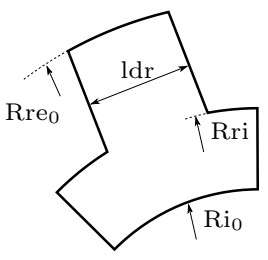

(b) Rotor

Fig. 15. Optimization design parameters in the stator and the rotor

TABLE III

DESIGN PARAMETERS

\begin{tabular}{ll}
\hline \hline Variables & $\begin{array}{l}\text { lsa, hsa, da, lds1, lds2, l5 } \\
\text { Rexc1, Rexc2, Rsi, ldr, Rri }\end{array}$ \\
Fixed or deduced & Rse $_{0}, R R_{0}, R_{0}$ \\
\hline \hline
\end{tabular}

generating all design variables for each particle $\operatorname{Prt}_{i}$ in the actual iteration $I t e_{i}$. At the next step, matlab parallel pool is launched in order to perform multiple particle evaluations at the same time $\left(\begin{array}{llll}\operatorname{Prt}_{1} & \ldots & \mathrm{Prt}_{W}\end{array}\right)$. The number of workers $W$ has been set to 10 in our case. This will reduce significantly optimization time as we will see later on. The flux-linkage per turn $\phi_{0}$ and the weight are determined at first. At this stage, we can't evaluate $C_{1}\left(U_{D C 0-13000}\right)$ because the number of turns per armature coil $n_{t c}$ is not fixed yet. In fact, if we go back to (7), we will see that the phase cyclic inductance $L$, the back-EMF $E$ and eventually the generated power $P_{D C}$ all depend on $n_{t c}$ which should be carefully chosen. Therefore we looked for an analytical approach in order to determine an optimal number of turns $\left(n_{t c}=n_{\text {opt }}\right)$ that will allow the generator to deliver its maximum possible power. After writing 


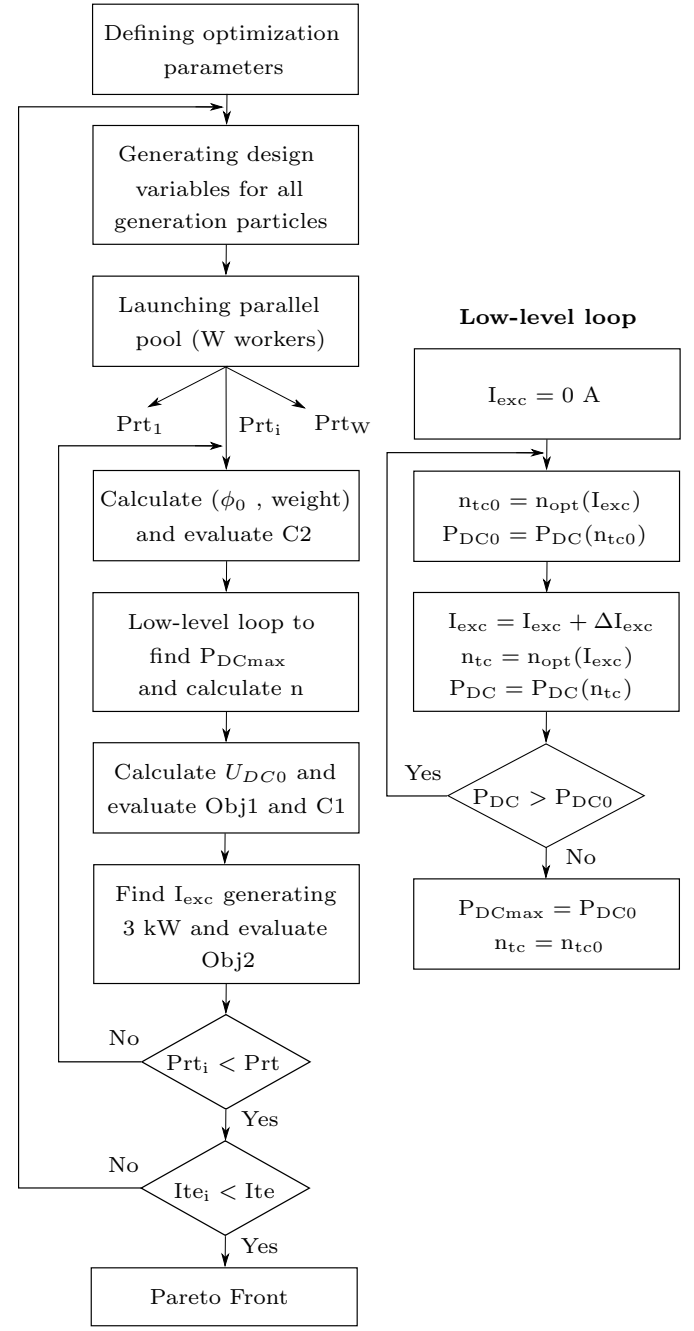

Fig. 16. Optimization flowchart

$L$ and $E$ as a function of $n_{t c}$, we looked for the derivative :

$\frac{d P_{D C}}{d n_{t c}}=\frac{A\left(I_{e x c}\right)}{\phi_{M}\left(I_{e x c}\right) N} \frac{-2 n_{t c}^{2} \phi_{M}^{2}\left(I_{e x c}\right) N^{2}+4 B^{2}}{2 n_{t c}^{3} \sqrt{n_{t c}^{2} \phi_{M}^{2}\left(I_{e x c}\right) N^{2}-B^{2}}}=0$

Resolving (12) allows us to determine $n_{\text {opt }}$ :

$$
n_{\text {opt }}\left(I_{\text {exc }}\right)=\sqrt{\frac{2 B^{2}}{\phi_{M}\left(I_{e x c}\right) N^{2}}}
$$

with $A$ depending on the excitation current and $B$ a constant. This result means that $n_{\text {opt }}$ is a function of the no-load fluxlinkage per turn and the rotational speed. In our case, $N$ is fixed as we look to maximize the power at $6000 \mathrm{rpm}$ but for $\phi_{M}$, it will depend on the excitation current. Therefore a low-level loop is introduced and $n_{\text {opt }}$ is found as shown in Fig. 16. $O b j 1$ and $C 1$ can now be evaluated and at the next step, $I_{\text {exc }}$ generating $3 \mathrm{~kW}$ at $12500 \mathrm{rpm}$ is found and the efficiency is determined. Table IV presents a comparison of optimization time ${ }^{2}$ between the static and the transient model. In order to perform the 50 iterations $* 100$ particles optimization, the SFE model took a total of 133 hours with all
TABLE IV

OPTIMIZATION TIME COMPARISON

\begin{tabular}{lcc}
\hline \hline & SFE & TFE \\
\hline $\begin{array}{l}\text { With mesh import } \\
\text { and parallel processing }\end{array}$ & $133 \mathrm{~h}$ & $2000 \mathrm{~h}$ \\
Without parallel processing & $1330 \mathrm{~h}$ & $20000 \mathrm{~h}$ \\
Without mesh import & $290 \mathrm{~h}$ & $\mathrm{X}$ \\
\hline \hline
\end{tabular}

the time reducing techniques mentioned before (mesh import, parallel processing). Using the transient model in the same conditions would increase that time up to 2000 hours. Without parallel processing, the optimization time would have been multiplied by 10 which is the number of workers used in parallel pool. Finally, without mesh import, the optimization time using the SFE would have increased from 133 to 290 hours. These results show that FE models can be used in optimization routines if appropriate time reducing techniques are exploited.

\section{Results and discussion}

We will present in this section the results of the optimization performed on the HEFSM using the same magnetic materials as in the prototype, i.e., $\mathrm{CoFe}$ in the stator and $\mathrm{SiFe}$ in the rotor. After choosing an optimized design from the Pareto front, we will compare its performances to the prototype using the transient model. This will allow us to determine the core losses $P_{\text {coreloss }}$ in both machines for an output power of $3 \mathrm{~kW}$ at $12500 \mathrm{rpm}$ and therefore calculating the "global" efficiency $\eta_{\text {global }}$ as shown in (14) :

$$
\eta_{\text {global }}=\frac{P_{\text {elect }}}{P_{\text {elect }}+P_{\text {exc }}+P_{\text {arm }}+P_{\text {coreloss }}}
$$

with $P_{\text {elect }}$ determined using (5). We should draw attention here once again that the core losses have not been taken into account in the optimization phase for computational time considerations and that $O b j 2$ has been evaluated using (11).

Figure 17 shows the Pareto front with the maximum generated power at $6000 \mathrm{rpm}$ and the efficiency respectively on the $\mathrm{x}$ and $\mathrm{y}$-axis. The chosen design $M$ represents the machine with the highest generated electromagnetic power

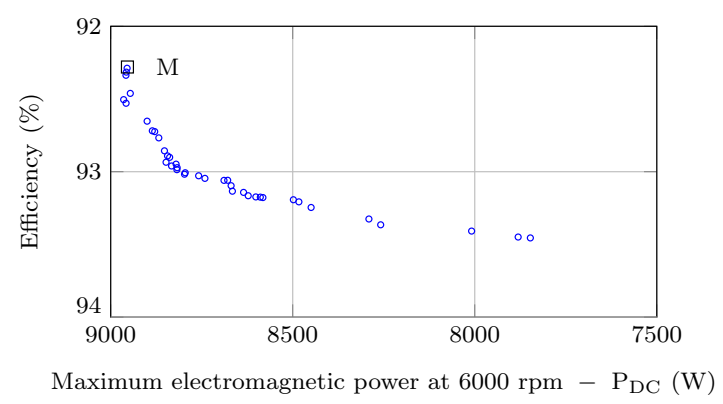

Fig. 17. Optimization Pareto front 


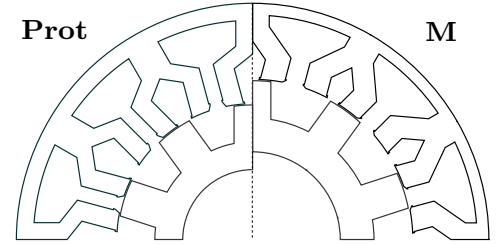

(a)

Fig. 18. Geometry comparison between the prototype and M

TABLE V

OPTIMIZATION RESULTS

\begin{tabular}{lll}
\hline \hline Parameter & Prot & M \\
& & \\
$\mathrm{P}_{\text {DCmax }}(6000 \mathrm{rpm})$ & $6000 \mathrm{~W}$ & $8900 \mathrm{~W}$ \\
$\mathrm{U}_{\text {DC0 }-13000}$ & $210 \mathrm{~V}$ & $15.75 \mathrm{~V}$ \\
$\eta_{\text {global }}(3 \mathrm{~kW}-12500 \mathrm{rpm})$ & $71 \%$ & $80 \%$ \\
$\mathrm{P}_{\text {coreloss }}(3 \mathrm{~kW}-12500 \mathrm{rpm})$ & $750 \mathrm{~W}$ & $450 \mathrm{~W}$ \\
$\mathrm{P}_{\text {exc }}(3 \mathrm{~kW}-12500 \mathrm{rpm})$ & $380 \mathrm{~W}$ & $160 \mathrm{~W}$ \\
$\mathrm{P}_{\text {arm }}(3 \mathrm{~kW}-12500 \mathrm{rpm})$ & $100 \mathrm{~W}$ & $120 \mathrm{~W}$ \\
hsa & $10.3 \mathrm{~mm}$ & $6.58 \mathrm{~mm}$ \\
AG radius & $40.07 \mathrm{~mm}$ & $47.3 \mathrm{~mm}$ \\
Weight & $3.5 \mathrm{~kg}$ & $3.1 \mathrm{~kg}$ \\
$\mathrm{n}_{\text {tc }}$ & 28 & 20 \\
PTW ratio $(6000 \mathrm{rpm})$ & $1.7 \mathrm{~kW} / \mathrm{kg}$ & $2.8 \mathrm{~kW} / \mathrm{kg}$ \\
& & \\
\hline \hline
\end{tabular}

with $\mathrm{P}_{\mathrm{DC}}=8900 \mathrm{~W}$. Its geometry is presented in Fig. 18 next to the prototype (Prot) and some of their performances are listed in table V. In comparison with the prototype, the optimized design complies with the safety regulations as it has a remanent voltage of only $15.75 \mathrm{~V}$ at $13000 \mathrm{rpm}$. This is mainly due to the much smaller permanent magnets with hsa $=6.58 \mathrm{~mm}$. However, if we look in Fig. 19, we will realize that the maximum no-load flux-linkage per turn $\left(\phi_{\max }\right)$ in $M$ is $35 \%$ higher than in the prototype and that the ratio between $\phi_{\max }$ and $\phi_{0}$ (the flux-linkage for $\mathrm{I}_{\mathrm{exc}}=0 \mathrm{~A}$ ) is equal to 60 in $M$ and only 5 in the prototype. This proves that despite having a very small remanent voltage, an optimal design of the HEFSM can still have very good "hybrid" performances which cannot be obtained in any other machine. One of the reasons behind this high flux-linkage is the increase of the Air-Gap (AG) radius from $40.07 \mathrm{~mm}$ to $47.3 \mathrm{~mm}$ which makes the stator more compact and helps reduce total weight $(3.1 \mathrm{~kg})$. The wider stator teeth reduce the saturation at high excitation current and make the excitation coils much more efficient. This allows better flux and power regulation. This can be seen in Fig. 20 where the generated power in $M$ increases much rapidly that in the prototype and reach a maximum of $8900 \mathrm{~W}$ in comparison with only $6000 \mathrm{~W}$ generated by the prototype. We can also notice in this figure that the power transfer in $M$ begins at a higher excitation current density $\left(10 \mathrm{~A} / \mathrm{mm}^{2}\right)$ due to a smaller phase flux-linkage at this stage than in the prototype. The efficiency is also considerably higher in the new design. With less core losses and less copper losses in the excitation coils, $\eta_{\text {global }}$ rises up to reach $80 \%$. These high performances are also due to the optimal number of

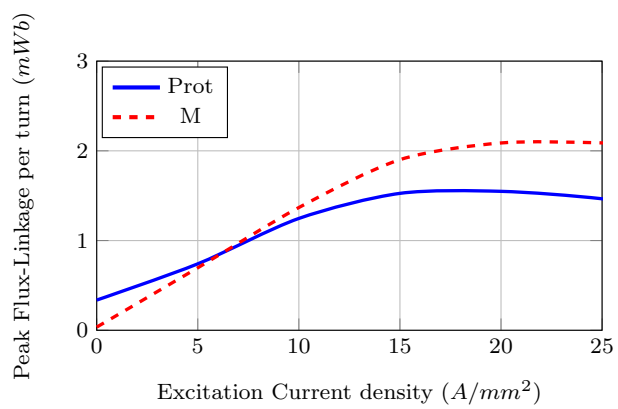

Fig. 19. Flux per turn per phase comparison

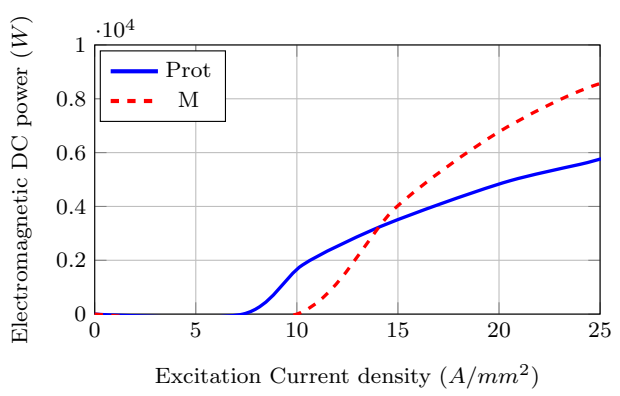

Fig. 20. Electromagnetic DC power comparison at $6000 \mathrm{rpm}$

turns per armature coil $n_{t c}$ calculated using the low-level loop integrated in the optimization. The optimized design has also a very good Power-to-Weight (PTW) ratio of $2.8 \mathrm{~kW} / \mathrm{kg}$. Using $\mathrm{CoFe}$ in both the stator and the rotor would have surely led to even higher power densities, however, with the Cobalt prices up to 20 times the prices of silicon metal, a cost/performance study is needed in order to evaluate the gains for such a low power rated prototype.

\section{CONCLUSION}

Hybrid machines are usually favored in wide-speed-range embedded applications due to their flux control capability and their high power density. However, their high remanent voltage causes safety concerns in critical applications like aircraft power generation, therefore, wound-field machines are used instead. This paper has presented a design optimization methodology of a hybrid-excited flux-switching machine for aircraft DC power generation in order to find the right balance between safety considerations and high performances. The structure studied in this paper has a stator and rotor made respectively of $\mathrm{CoFe}$ and $\mathrm{SiFe}$ sheets. It has been shown that despite having a very small remanent flux-linkage, an optimal design of the HEFSM can have very good performances with a high power-to-weight ratio. These results are very interesting for the aviation industry as it makes the HEFSM a possible candidate for future aircraft DC power generation.

\section{REFERENCES}

[1] S. Stipetic, W. Miebach, and D. Zarko, "Optimization in design of electric machines: Methodology and workflow," in 2015 Intl Aegean Conference on Electrical Machines Power Electronics (ACEMP), 2015 
Intl Conference on Optimization of Electrical Electronic Equipment (OPTIM) 2015 Intl Symposium on Advanced Electromechanical Motion Systems (ELECTROMOTION), DOI 10.1109/OPTIM.2015.7427030, pp. 441-448, Sep. 2015.

[2] J. A. Vasconcelos, R. R. Saldanha, L. Krahenbuhl, and A. Nicolas, "Genetic algorithm coupled with a deterministic method for optimization in electromagnetics," IEEE Transactions on Magnetics, vol. 33, DOI 10.1109/20.582645, no. 2, pp. 1860-1863, Mar. 1997.

[3] C. Ma and L. Qu, "Multiobjective optimization of switched reluctance motors based on design of experiments and particle swarm optimization," IEEE Transactions on Energy Conversion, vol. 30, DOI 10.1109/TEC.2015.2411677, no. 3, pp. 1144-1153, Sep. 2015.

[4] B. N. Cassimere and S. D. Sudhoff, "Population-based design of surfacemounted permanent-magnet synchronous machines," IEEE Transactions on Energy Conversion, vol. 24, DOI 10.1109/TEC.2009.2016150, no. 2, pp. 338-346, Jun. 2009.

[5] W. Jiang, T. M. Jahns, T. A. Lipo, W. Taylor, and Y. Suzuki, "Machine design optimization based on finite element analysis in a high-throughput computing environment," in 2012 IEEE Energy Conversion Congress and Exposition (ECCE), DOI 10.1109/ECCE.2012.6342727, pp. 869876, Sep. 2012.

[6] G. J. Li, Z. Q. Zhu, and G. Jewell, "Performance investigation of hybrid excited switched flux permanent magnet machines using frozen permeability method," IET Electric Power Applications, vol. 9, DOI 10.1049/iet-epa.2015.0129, no. 9, pp. 586-594, 2015.

[7] A. S. Thomas, Z. Q. Zhu, and G. J. Li, "Electromagnetic loss investigation and mitigation in switched flux permanent magnet machines," in 2014 International Conference on Electrical Machines (ICEM), DOI 10.1109/ICELMACH.2014.6960326, pp. 1146-1152, Sep. 2014.

[8] G. Li, J. Ojeda, E. Hoang, and M. Gabsi, "Double and single layers fluxswitching permanent magnet motors: Fault tolerant model for critical applications," in 2011 International Conference on Electrical Machines and Systems, DOI 10.1109/ICEMS.2011.6073664, pp. 1-6, Aug. 2011.

[9] A. S. Thomas, Z. Q. Zhu, and G. J. Li, "Thermal modelling of switched flux permanent magnet machines," in 2014 International Conference on Electrical Machines (ICEM), DOI 10.1109/ICELMACH.2014.6960491, pp. 2212-2217, Sep. 2014.

[10] G. Li, J. Ojeda, E. Hoang, M. Gabsi, and M. Lecrivain, "Thermalelectromagnetic analysis for driving cycles of embedded flux-switching permanent-magnet motors," IEEE Transactions on Vehicular Technology, vol. 61, DOI 10.1109/TVT.2011.2177283, no. 1, pp. 140-151, Jan. 2012.

[11] E. Hoang, M. Lecrivain, and M. Gabsi, "A new structure of a switching flux sunchronous polyphased machine with hybrid excitation," European Conference on Power Electronics and Applications, 2 - 7 Sept 2007.

[12] E. Hoang, M. Lecrivain, and M. Gabsi, "Flux-switching dual excitation electrical machine," Patent Us 7868506 B2, Jan 11, 2011.

[13] A. Nasr, M. Gabsi, S. Hlioui, M. Mairie, and D. Lalevee, "Experimental investigation of a doubly-excited flux-switching machine for aircraft dc power generation," in IEEE International Electric Machines \& Drives Conference, Miami, Florida, 2017.

[14] Y. Wang and Z. Q. Deng, "Analysis of electromagnetic performance and control schemes of electrical excitation flux-switching machine for dc power systems," IEEE Transactions on Energy Conversion, vol. 27, DOI 10.1109/TEC.2012.2215920, no. 4, pp. 844-855, Dec. 2012.

[15] S. Hlioui, Y. Amara, E. Hoang, and M. Gabsi, "Overview of hybrid excitation synchronous machines technology," in 2013 International Conference on Electrical Engineering and Software Applications, DOI 10.1109/ICEESA.2013.6578499, pp. 1-10, Mar. 2013.

[16] M. Cossale, A. Krings, J. Soulard, A. Boglietti, and A. Cavagnino, "Practical investigations on cobalt iron laminations for electrical machines," IEEE Transactions on Industry Applications, vol. 51, DOI 10.1109/TIA.2015.2394404, no. 4, pp. 2933-2939, Jul. 2015.

[17] I. Jadric, D. Borojevic, and M. Jadric, "A simplified model of a variable speed synchronous generator loaded with diode rectifier," IEEE Power Electronics Specialists Conference, pp. 497 - 502, 22 - 27 Jun 1997.

[18] J. Aubry, H. B. Ahmed, and B. Multon, "Sizing optimization methodology of a surface permanent magnet machine-converter system over a torque-speed operating profile: Application to a wave energy converter," IEEE Transactions on Industrial Electronics, vol. 59, DOI 10.1109/TIE.2011.2163287, no. 5, pp. 2116-2125, May. 2012.

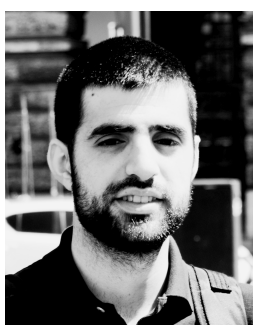

Andre Nasr is currently working toward the Ph.D. degree in electrical engineering at the SATIE laboratory of the Ecole Normale Superieure de Cachan, France. He received the B.Eng. degree in electrical and electronic engineering from the Lebanese University - Faculty of Engineering II, Lebanon and the M.Sc. degree in physics and energy engineering from the Ecole Superieure d'Electricite, Gif-sur-Yvette, France in 2014. His current research interests include modeling and design optimization of innovative topologies of electrical machines.

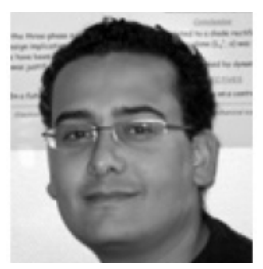

Sami Hlioui is lecturer at the CNAM, Paris, France and researcher at the SATIE laboratory of the Ecole Normale Superieure de Cachan, France. He obtained the electromechanical engineer diploma from the National School of Engineering of Sfax - Tunisia (ENIS) in 2004, his M.Sc. degree in electrical engineering from the Ecole Normale Superieure de Cachan, France and his Ph.D. degree in electrical power engineering from the University of Technology of Belfort-Montbeliard (UTBM), France, in 2008. His main research interest are the multidisciplinary modeling of electromagnetic actuators and the optimal design of these actuators for embedded applications.

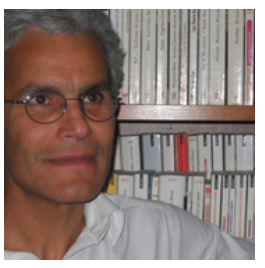

Mohamed Gabsi received the Ph.D. degree in electrical engineering from University of ParisVI, Paris, France, in 1987 and the HDR from the University of Paris-XI, Orsay, France, in 1999. Since 1990, he has been working with the electrical machines team SETE of the SATIE Laboratory, ENS Cachan, France, where he is currently a full Professor. His research interests include SRM, vibrations and acoustic noise, and PM machines.

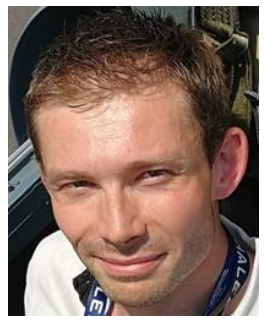

Mathieu Mairie is currently working at Thales Avionics Electrical Systems, Chatou, France. $\mathrm{He}$ received the engineer diploma from the Ecole Superieure d'Electricite (SUPELEC), Gifsur-Yvette, France in 2009. His current work includes study of innovative topologies of electrical machines and development of static power converter for aerospace.

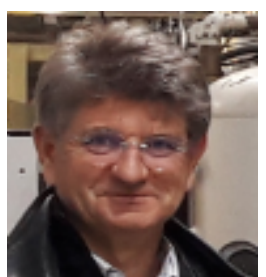

Didier Lalevee has graduated from ENSAM engineering school, Paris in 1980 . He is currently working at THALES Avionics Electrical Systems. After holding various positions in the Aeronautical business, he currently is the Project Manager of the R\&T GENOME project where THALES leads the WP3 (Work Package 3) for Generation \& Conversion applications for MEA (More Electrical Aircraft) under AIRBUS leadership. 